\title{
Acil Servise Başvuran Hipertansiyon Hastalarının Klinik Özellikleri ve Acil Servise Başvuru Sıklığını Etkileyen Faktörlerin İncelenmesi
}

\section{The Clinical Features of the Hypertension Patients Who Apply to Emergency Service and Investigation of Factors Affecting Frequency of Application to the Emergency Service}

\author{
Canan Akman ${ }^{1}$, Ercan Akşit ${ }^{2 *}$ \\ ${ }^{1}$ Çanakkale Onsekiz Mart Üniveristesi, Acil Tıp Ana Bilim Dalı, Çanakkale, Türkiye \\ ${ }^{2}$ Çanakkale Onsekiz Mart Üniveristesi, Kardiyoloji Ana Bilim Dalı, Çanakkale, Türkiye \\ e-posta: cananakman@comu.edu.tr, ercanaksit@comu.edu.tr \\ ORCID: 0000-0002-3427-5649 \\ ORCID: 0000-0002-4478-4322 \\ *Sorumlu yazar/Corresponding author: Ercan Akşit ${ }^{1}$ \\ Gönderim tarihi/Received:03.05.2020 \\ Kabul tarihi/Accepted:05.06.2020 \\ DOI: $10.34087 /$ cbusbed.731511 \\ Öz
}

Giriş ve Amaç: Acil servis doktorları yüksek kan basıncı nedeniyle acil servise başvuran hastalar ile sık olarak karşılaşmaktadır. Bu çalışmanın amacı, acil servise başvuran hipertansiyon hastalarının klinik özelliklerini ve acil servise başvuru sıklığını etkileyen faktörleri incelemektir.

Gereç ve Yöntemler: Bu çalışmaya hastanemiz acil servisine başvuran daha önce hipertansiyon tanısı olan 100 gönüllü hasta alınmıştır. Araştırmanın veri toplama aşamasında yüz yüze görüşülerek anket uygulanmıştır.

Bulgular: Hastaların \%52'sinde 10 yıldan fazladır hipertansiyon mevcuttu. Hastaların \%81'ine yaşam tarzı değişikliği hakkında bilgilendirme yapılmıştır. Hastaların sadece \%32'sine acil durumda kullanması için ilaç reçete edilmiştir. Takipte olduğu doktor tarafından, hipertansiyonun uç organlarına zarar verebileceği hastaların yalnız \%40'ına anlatılmıştır. Son bir yıl içinde hipertansiyon nedeni ile iki veya daha fazla sayıda acil servise başvuran hasta oranı $\% 57$ 'dir.

Sonuç: Bu çalışma hipertansiyon tanısı ile bir yıl içinde iki veya üstü sayı ile acil servise başvurunun olduğunu göstermektedir. Hipertansiyon hastalarına hastalıkları hakkında ayrıntılı bilgilendirme yapmak hastaların acil servise başvuru sıklıklarını azaltabilir.

Anahtar Kelimeler: Hipertansiyon, acil servis, bilgilendirme

\begin{abstract}
Objective: Emergency service physicians often deal with patients presenting to emergency service with high blood pressure. The aim of this study is to examine the clinical features of hypertension patients who apply to emergency service and factors that affecting frequency of application to the emergency service.

Materials and Methods: This study was participated by a total of 100 volunteer patients who were previously diagnosed with hypertension and presented to the emergency service in our hospital. The data of the study were collected through surveys in face to face interviews.

Results: Hypertension was present in $52 \%$ of the patients for more than 10 years. $81 \%$ of the patients were informed about life-style changes. Only $32 \%$ of the patients were prescribed medication for emergency use. Also, only $40 \%$ of the patients were informed by their doctors about the fact that hypertension may damage end-organs. Due to hypertension, $57 \%$ of the patients presented to the emergency service twice or more times in the last 1 year.

Conclusion: This study shows that many patients diagnosed with hypertension have visited emergency service twice or more times in the last one year. Providing hypertension patients with detailed information about their diseases can reduce the frequency of patients admission to the emergency service.
\end{abstract}

Key words: Hypertension, emergency service, informing 


\section{Giriş}

Hipertansiyon, arter içi kan basıncının artması ile karakterize genetik, edinsel ve metabolik nedenlerin sebep olduğu önemli mortalite ve morbibitesi olan bir sendrom olarak tanımlanmaktadır [1]. Amerika Kalp Cemiyetinin klavuzuna göre ise $130 / 80 \mathrm{mmHg}$ ve üzeri, Avrupa Kardiyoloji Topluluğu klavuzuna göre 140/90 mmHg ve üzeri ölçümler hipertansiyon olarak tanımlanmaktadır [2,3]. Hipertansiyon end-organları etkileyerek mortal seyredebilmekte, uygulanan ilaç tedavisi ve beraberinde yapılan yaşam tarzı değişiklikleri ise bu hastalığa bağlı morbibite ve mortaliteyi azaltmaktadır [4,5]. $\mathrm{Bu}$ amaçla hipertansiyon tedavisi ile birlikte hastanın bilgilendirilmesi, hipertansiyona karşı farkındalığının arttırılması hipertansiyonun yönetiminde en önemli halkalardan birini oluşturmaktadır [6]. Türkiye'de hipertansiyon prevelansı \%32 civarında olduğu, hipertansiyon için tarama yapıldığında hastalığının farkında olanların oranının \%54,7 olduğu, ilaç tedavisi alan hasta oranın ise \%47,4 olmasına karşın hastaların ancak \%28,7'sinde hedef kan basıncına ulaşılabildiği rapor edilmesi nedeni ile Türk hipertansiyon uzlaşı raporunda hipertansiyon prevelansının ülkemiz için yüksek, tanı ve tedavinin ise yeterli olmadığı görüşü belirtilmiştir [7].

Literatürde, bildiğimiz kadarı ile, hipertansiyon tedavisine uyumun ve hastaların hipertansiyon hastalığ hakkında farkındalık seviyelerinin özellikle acil servise başvuru sıklıkları üzerine etkisi ile ilgili makale yoktur. Bu sebebten bu çalışmada; acil servise hipertansiyon ile başvuran hastaların klinik özellikleri ve acil servise başvuru sıklığını etkileyen faktörlerin incelenmesi hedeflenmiştir.

\section{Materyal ve Metot}

$\mathrm{Bu}$ araştırma tanımlayıcı tipte olup 16.01.2019 ve 16.04.2019 tarihleri arasında hastanemiz acil servisinde yapıldı. Araştırmanın hedef popülasyonu acil servisimize, daha önce tanısı konmuş, hipertansiyon ile başvuran 18 yaş üzerindeki gönüllü hastalar olarak belirlenmiştir. Çalışmadan dışlama kriteri olarak, hastaların çalışmaya katılmak istememeleri, demans gibi kognitif bozukluğu olması olarak belirlendi. Bu tarihler arasında çalışmaya kriterlere uyan 100 hasta dahil edilmiştir. Veri toplama aşaması kardiyoloji ve acil hekimleri tarafından yürütülmüştür. Çalışmaya katılmayı gönüllü olarak kabul eden katılımcılara çalışmanın amaç ve yöntemi hakkında hekimlerce bilgi verildi, katılımcıların sözlü ve yazılı onamları alındı. Çalışmaya katılanlara anket formlarından 23 soru yöneltildi. Anket formundaki sorular, literatürdeki hipertansiyon farkındalığının araştırıldığı anket çalışmalarındaki sorulara benzer hazırlandı [8]. Anket sorularımız üç temel bölümden oluşmaktadır. Birinci bölümde katılımcılara; demografik özellikleri, eğitim ve gelir durumları, yaşadıkları yer, sigara ve alkol kullanımı ile komorbid durumları yönünden sorular yöneltildi. İkinci bölümde katılımcılara; kaç yıldır hipertansiyon hastası oldukları, kullandıkları ilaçlar, hipertansiyon ilacinın ilk ne zaman ve hangi klinik branşca başlandığı, medikal tedavi ve yaşam tarzı değişikliği hakkında bilgi sahibi olup olmadıkları, evde tansiyonun nasıl ölçülmesi gerektiği hakkında bilgilendirme alıp almadıklarına yönelik sorular soruldu. Son kısımda ise, bir yıl içinde acil servise kaç kez başvurdukları, acil servise başvuru sırasındaki şikayetleri, hangi durumlarda acil servise müracat etmeleri gerektiği hakkında bilgilerinin olup olmadıkları, acil servise başvurmadan önce tansiyon ölçüp ölçmedikleri, acil durumlar için ek ilaç reçete edilip edilmediği, kendilerine hipertansiyonun uç organları etileyebileceği ve her yıl düzenli tetkik yaptırmaları gerekliliği konusunda hekimleri tarafından bilgi verilip verilmediğine dair sorular yöneltildi. İlk iki kısım, litearatürde daha önce yapılan çalımalarda hipertansiyon hastalarına yöneltilen, hipertansiyon hastalığı hakkında hastaların farkındalıklarını araştıran sorulardır [8]. Son kısım ise literatürde daha önce sorgulanmamış ve hastaların hipertansiyon nedeni ile acil servise başvuru sıklığını etkileyebilecek faktörlerin sorgulandığı bölümdür.

Araştırma öncesinde hastanemiz Klinik Araştırmalar Etik Kurulu'ndan izin alındı (Karar No :2019-02).

Veriler SPSS Paket Program 20.0 sürümü ile analiz edilmiştir. Tanımlayıcı verilerin sunumunda sayı, yüzde, ortalama, ortanca, standart sapma, minimum ve maksimum kullanılmıştır. Kategorik değişkenlerin karşılaştırmasında $\mathrm{Ki}$ Kare Testi kullanılmıştır. İstatistiksel anlamlılık için $\mathrm{p}<0.05$ kabul edilmiştir.

\section{Bulgular ve Tartışma}

Çalışmaya katılanların \%60'ını $\quad(n=60)$ kadınlar oluşturmaktadır. Katılımcıların yaş ortalaması $68.6 \pm 11.7$ 'dir. Yaşadıkları yer \%63 $(n=63)$ ile şehir merkezidir. Gelir düzeyi \%72 orta düzeydedir. \%48'i bir işte çalışmaktadır. Çalışma katılan hastaların \%66's1 medeni durumunu evli olarak bildirmiştir (Tablo1). \% 54'ü daha önce hiç sigara içmemiş, \%81'i daha önce hiç alkol kullanmamıştır. \%62'sinin komorbit hastalığı vardır. Diyabetes mellitus en sık eşlik eden komorbit hastalık olarak saptanmıştır (Tablo 2).

Çalışma grubunun\%52'sinde ( $\mathrm{n}=52) 10$ yıldan fazla hipertansiyon hastalığı mevcuttur. \%62'si düzenli olarak tansiyon aleti ile ölçüm yapmaktadır. Sık olarak kullandıkları ilaç grubu ise $\% 62$ ile ACE inhibitörüdür. Katılımcılara tedavisi başlanmadan önce \%81'ine yaşam tarzı değişikliği hakkında bilgilendirme yapılmıştır. Evde nasıl tansiyon ölçüleceği sağlık personeli tarafından \%33'üne anlatılmıştır. Hangi durumda acil servise başvurması gerektiği hakkında bilgilendirme \%36'sına yapılmıştır. \%32'sine acil durumda kullanması için ilaç reçete edilmiştir. Hipertansiyon nedeni ile takipte olduğu doktoru tarafından, hipertansiyonun uç organlarına 
Tablo 1. Çalışmaya katılan hastaların sosyodemografik özellikleri

\begin{tabular}{|c|c|}
\hline Değişkenler & n $(\%)$ \\
\hline \multicolumn{2}{|l|}{ Cinsiyet } \\
\hline Kadın & $60(60.0)$ \\
\hline \multicolumn{2}{|l|}{ Eğitim durumu } \\
\hline Okuryazar değil & $18(18.0)$ \\
\hline İlköğrenim & $61(61.0)$ \\
\hline Lise & $9(9.0)$ \\
\hline Yüksekokul & $12(12.0)$ \\
\hline \multicolumn{2}{|l|}{ Yaşadığı yer } \\
\hline Merkez & $63(63.0)$ \\
\hline İlçe & $18(18.0)$ \\
\hline Köy ve belde & $19(19.0)$ \\
\hline \multicolumn{2}{|l|}{ Gelir durumu } \\
\hline Kötü & $3(3.0)$ \\
\hline Orta & $72(72.0)$ \\
\hline İyi & $25(25.0)$ \\
\hline \multicolumn{2}{|l|}{ Çalışma durumu } \\
\hline Emekli & $51(51.0)$ \\
\hline Gelir yok & $1(1.0)$ \\
\hline Çalışıyor & $48(48.0)$ \\
\hline \multicolumn{2}{|l|}{ Medeni durum } \\
\hline Evli & $66(66.0)$ \\
\hline \multirow[t]{2}{*}{ Bekar/Dul/boşanmış } & $34(34.0)$ \\
\hline & Ortalama \pm ss \\
\hline Yaş & $68.6 \pm 11.7$ \\
\hline Boy (m) & $1.67 \pm 0.1$ \\
\hline Kilo (kg) & $76.2 \pm 15.1$ \\
\hline
\end{tabular}

\%: sütun yüzdesi, ss: standart sapma

zarar verebileceği hastaların \%40'ına anlatılmıştır ve bu nedenle \%52'sine her yıl düzenli tetkik yaptırması gerektiği belirtilmiştir. \%59'u acil servise gelmeden önce evde tansiyonunu ölçmüştür. Acil servise en sık başvuru şikâyeti ise \%62 ile baş ağrısıdır (Tablo 3). Katılımcıların \%43'ü son bir y1l içinde bir kez acil servise başvurmuş olup, \%21 iki kez, \%11 üç kez, \%7 dört kez, \%18'i ise beş ve üzerindedir Hipertansiyon ilk tanısı katılımciların
Tablo 2. Hastaların alışkanlıkları ve komorbidite durumlarının dağılımı

\begin{tabular}{|c|c|}
\hline Değişkenler & n $(\%)$ \\
\hline \multicolumn{2}{|c|}{ Sigara kullanma durumu } \\
\hline Evet & $19(19.0)$ \\
\hline Kullanıp bırakmış & $27(27.0)$ \\
\hline Hayır & $54(54.0)$ \\
\hline \multicolumn{2}{|c|}{ Alkol kullanma durumu } \\
\hline Evet & $11(11.0)$ \\
\hline Kullanıp bırakmış & $8(8.0)$ \\
\hline Hayır & $81(81.0)$ \\
\hline \multicolumn{2}{|l|}{ Komorbidite durumu } \\
\hline Var & $62(62.0)$ \\
\hline \multicolumn{2}{|l|}{ Komorbidite } \\
\hline Diabet & $41(66.0)$ \\
\hline Hiperlipidemi & $6(1.0)$ \\
\hline Kalp yetersizliği & $6(1.0)$ \\
\hline İskemik inme & $6(1.0)$ \\
\hline Koroner arter hastalığ 1 & $21(34.0)$ \\
\hline
\end{tabular}

\%39'una dahiliye, \%23'üne aile hekimleri, \%21'ine kardiyoloji, \%14'üne acil hekimleri, \%3'üne nöroloji hekimleri tarafından konulmuştur.

Acil servise bir kez veya iki ve üzerinde başvuru açısından karşılaştırma yapıldığında: Acil servise bir kere başvuranların \%53,4'i $(n=23) 2 \mathrm{kez}$ ve üzeri başvuranların \%29,8'si (n=17) hipertansiyonunu takip eden doktoru tarafından ileride oluşabilecek end-organ hasarı açısından bilgilendirme yapıldığını belirtmişlerdir ve bu durum gruplar arasında anlamlı farka neden olmuştur $(p=0.029)$. Aynı şekilde hipertansiyonu takip eden doktoru tarafindan, ileride oluşabilecek end-organ hasarları açısından düzenli olarak tetkik yaptırması önerilmiş ve bilgilendirildiklerini belirtmişlerdir. Gruplar arasında bu fark da anlamlıdır ( $\mathrm{p}=0.038$ ).

Acil servise başvuru sayısına göre, ilaç tedavisi verilmeden önce doktoru tarafindan yaşam tarzı değişikliği hakkında bilgilendirme gruplar arasında anlamlı farka neden olmamıştır ( $\mathrm{p}=0.493)$ (Tablo 4).

$\mathrm{Bu}$ çalışma, bildiğimiz kadarı ile, hipertansiyon hastalarının acil servise başvurma sıklığını etkileyen faktörleri inceleyen ilk çalışmadır. Bu çalışmada, hastaları tanı aldıklarında end-organ hasarı konusunda bilgilendirmenin ve belirli aralıklar ile düzenli tetkik yaptırılması gerekliliği hakkında bilgilendirmenin, acil servise hipertansiyon tanısı ile başvuru sıklığını azalttığı gösterilmiştir. 
Tablo 3. Katılımcıların hastalık özellikleri ve hastalık hakkında bilinç düzeyleri

\begin{tabular}{|c|c|}
\hline & n $(\%)$ \\
\hline \multicolumn{2}{|l|}{ Hipertansiyon hastalığının süresi } \\
\hline 1yıl & $8(8.0)$ \\
\hline $1-10$ yıl & $40(40.0)$ \\
\hline 10 yıldan fazla & $52(52.0)$ \\
\hline \multicolumn{2}{|l|}{ Düzenli olarak tansiyon ölçümü } \\
\hline Evet & $62(62.0)$ \\
\hline \multicolumn{2}{|l|}{ Kullandıkları ilaç } \\
\hline Anjiotensin dönüştürücü enzim inhibitörü & $62(62.0)$ \\
\hline Anjiotensin reseptör blokeri & $21(21.0)$ \\
\hline Ca-kanal blokeri & $11(11.0)$ \\
\hline Beta bloker & $21(21.0)$ \\
\hline Diüretik & $4(4.0)$ \\
\hline \multicolumn{2}{|c|}{ Yaşam tarzı değişikliği hakkında bilgilendirme } \\
\hline Evet & $81(81.0)$ \\
\hline \multicolumn{2}{|c|}{ Sağlık personeli tarafından evde tansiyonun nasıl ölçüleceği hakkında bilgi verilmesi } \\
\hline Evet & $33(33.0)$ \\
\hline \multicolumn{2}{|c|}{ Hangi durumda acil servise başvuracağı hakkında bilgilendirme } \\
\hline Evet & $36(36.0)$ \\
\hline \multicolumn{2}{|c|}{ Acil durumlar için bilgilendirme ve reçete edilmesi } \\
\hline Evet & $32(32.0)$ \\
\hline \multicolumn{2}{|c|}{ Hipertansiyonun uç organlara zararı hakkında bilgilendirme } \\
\hline Evet & $40(40.0)$ \\
\hline \multicolumn{2}{|c|}{ Her yıl düzenli tetkik yapılması gerektiği hakkında bilgilendirme } \\
\hline Evet & $52(52.0)$ \\
\hline \multicolumn{2}{|c|}{ Acil servise gelmeden önce evde tansiyon ölçümü } \\
\hline Evet & $59(59.0)$ \\
\hline \multicolumn{2}{|l|}{ Acil servise başvuru şikâyeti } \\
\hline Baş dönmesi ve/veya bayılma & $32(32.0)$ \\
\hline Baş ağrısı & $62(62.0)$ \\
\hline Göğüs ağrisı ve/veya nefes darlı̆̆1 & $6(6.0)$ \\
\hline
\end{tabular}

\%: sütun yüzdesi

Hipertansiyon önlenebilen fakat end-organ hasarı geliștiğinde ise hayatı tehtid eden bir hastalık olmasının hasta tarafından anlaşılması, daha düzenli takiplerini yaptırmasına, daha düzenli ilaç almasına, bunlarda acil servis başvuru sıklığının azalmasına neden oluyor gözükmektedir. Türk hipertansiyon prevalans çalışmasında erişkin yaş grubunda hipertansiyon prevalans1 \%32, kadın ve erkek cinsiyetteki prevalans ise $\% 36.1$ ve $\% 27.7$ olarak belirilmiştir [9]. Yapılan diğer çalışmalar da kadınlarda hipertansiyon hastalığının yüksek oranda olduğu gösterilmiştir [10]. Bizim çalışmamızda da hipertansiyon hastalarının çoğunluğunu kadınlar (\%60) oluşturmakta idi. Diyabetes mellitus hastalığı olanlarda hipertansiyon, mikro ve makrovasküler düzeyde komplikasyonlara yol açan bir risk faktörü olarak karşımıza çıkmaktadır [11]. Çalışmamızda da komorbidite yönünden diyabetes mellitusun hipertansiyona en sık eşlik 
Tablo 4. Acil servise başvuru sayısına göre grupların hipertansiyon hakkında bilgilendirme durumlarının karşılaştırılması

\begin{tabular}{|c|c|c|c|}
\hline & \multicolumn{2}{|c|}{ Acil Servise Başvuru Sayısı } & \multirow[b]{3}{*}{$\mathbf{p}$} \\
\hline & $\begin{array}{c}1 \text { kez başvuru } \\
(\mathrm{n}=43)\end{array}$ & $\begin{array}{l}2 \text { ve üzeri başvuru } \\
(\mathrm{n}=57)\end{array}$ & \\
\hline & n $(\%)$ & n $(\%)$ & \\
\hline \multicolumn{4}{|c|}{$\begin{array}{l}\text { İlaç tedavisi verilmeden önce doktor tarafindan yaşam tarzı } \\
\text { değişikliği önerileri }\end{array}$} \\
\hline Evet & $33(76.7)$ & $48(84.2)$ & 0.493 \\
\hline \multicolumn{4}{|c|}{ Evde tansiyonun nasıl ölȩüleceği hakkında bilgilendirme } \\
\hline Evet & $17(39.5)$ & $16(28.0)$ & 0.321 \\
\hline \multicolumn{4}{|c|}{$\begin{array}{l}\text { Hangi şikayeti olursa tansiyon ölçümünü tekrarlaması ve } \\
\text { hangi durumda acil servise başvurması hakkında } \\
\text { bilgilendirme }\end{array}$} \\
\hline Evet & $17(39.5)$ & 19(33.3) & 0.668 \\
\hline \multicolumn{4}{|c|}{$\begin{array}{l}\text { Acil durumda tansiyonun düşmesi için sadece lüzümü halinde } \\
\text { hap içilmesi hakkında bilgilendirme }\end{array}$} \\
\hline Evet & $10(23.2)$ & $22(38.5)$ & 0.158 \\
\hline \multicolumn{4}{|c|}{$\begin{array}{l}\text { Doktoru tarafindan ileride oluşabilecek end-organ hasarına } \\
\text { karşı bilgilendirme }\end{array}$} \\
\hline Evet & 23(53.4) & 17(29.8) & 0.029 \\
\hline \multicolumn{4}{|c|}{$\begin{array}{l}\text { Takip eden doktoru tarafından ileride oluşabilecek end-organ } \\
\text { hasarı açısından her yıl düzenli tetkik yaptırılması veya } \\
\text { bilgilendirilmesinin yapılması }\end{array}$} \\
\hline Evet & $28(65.1)$ & $24(42.1)$ & 0.038 \\
\hline
\end{tabular}

eden hastalık olduğu görülmüştür. Kan basıncındaki değişkenliğin saptanmasında önerilen klinik uygulamardan biri de evde kan basıncının ölçülmesidir $[12,13]$. Çalışmamıza katılan hastaların \%62'si evde düzenli olarak hergün kan basıncını ölçtüklerini belirtmişlerdir. Hastaların \%59'u ise acil servise gelmeden önce evde tansiyonlarını ölçmüşlerdir. Çalışma grubundaki hastaların \%67'si evde nasıl tansiyon ölçülmesi gerektiği hakkında bilgiye sahip değildir ve \%68'ine acil durumda kullanabilmesi için doktoru tarafından ilaç bilgilendirilmesi yapılmadığı ve reçete yazılmadığı görülmektedir. Hipertansiyon tedavisi ile ilgili adımlarda yaşam tarzı değişiklikleri son derece önemlidir ve kan basıncını anlamlı olarak azaltmaktadır [14,15]. Çalışmamızda hastalara \%81 oranında ilaç tedavisine başlamadan yaşam tarzı değişikliği hakkında bilgilendirmenin doktorlar tarafından yapıldığını görmekteyiz. Fakat hipertansiyon hastalarının \% 60'ına ilaç başlamadan hekimleri tarafindan, hipertansiyonun end-organlara zararı konusunda bilgi verilmediği görülmektedir. Bunun önemli bir nedeni olarak, Türkiye'de hekimlerin mesai saatlerinde yoğun hasta yüküne maruz kalmaları hasta bilgilendirmesinde eksiklikler görülmesinde rol oynuyor olabilir. Çalışmamızda hipertansiyon tanısı ile bir yıl içinde iki veya üstünde sayı ile acil servise başvurunun sık olduğu görülmektedir. Ulusal çekirdek eğitim programınında tıp fakültesini bitiren tüm doktorların hipertansiyonu tanıyı tedavi etmesi, izlemesi, her aşama ve derecede koruyucu hizmetleri vermesi, acil durumda müdahale edip tedavi etmesini bilerek mezun olmasını önermektedir [16]. Çalışmamızda hastalara hipertansiyon ilacını ilk başlayan kliniğin \%39 ile en s1k dahiliye olduğu görülmekte ve aile hekimlerinin oranı ise $\% 23$ olarak saptanmıştır. Güncel klavuzlar hipertansiyon hastasına en az ayrılması gereken süreyi 26 dakika olarak belirlemişlerdir [17]. Ülkemizdeki hekimlerin çoğu yoğun hasta yükü altında olduklarından, bir hastaya ayrılan ortalama süre bu sürenin çok altındadır. Hipertansiyon hastalarına uygulanan eğitim ve sonrasında yapılan izlemlerde, hastaların yaşam tarzındaki olumlu değişimlerin ilaç tedavisine olan uyumu arttırdığı görülmüştür [18]. Koruyucu kardiyoloji eğitim hemşiresi programının yaygınlaşması, aile hekimleri ile bu hastaları koordineli 
ve düzenli takip etmeleri bu hastaların hem acil servise başvurularını hem de bu hastalığa bağlı mortalite ve morbibitelerini azaltabilir. Yildırım ve ark. [19] yakın zamanda yaptıkları çalışmada belirttikleri gibi, bilişim tabanlı uygulamaların kronik hastalık izleminde kullanılmasının, hastaların yaşam kalitelerini, özbakım becerilerini, en önemlisi de hastalıkları hakkındaki bilgi düzeylerini ve farkındalıklarını arttarttırdığını, buna karşılık iş yükünü ve maliyeti azalttığını belirmişlerdir.

Çalışmamızın en önemli kısıtlılığı hastaların herhangi bir acil servise başvuru sıklıklarının kendi beyan ettikleri kadarı ile öğrenilmesi idi. Daha önce diş merkez acil servislere bassvuruldu ise bunu doğrulayacak epikriz belgelerine ulaşılamadı. Ayrıca hastalara her ne kadar semptomatik rahatlama sağlanıp acil servisten taburcu olmadan önce anket soruları yöneltilmiş olsa da, hem acil serviste olmaları hem kaygı düzeylerinin o an yüksek olması, anket sorularına optimal cevap vermelerini etkilemiş olabilir.

\section{Sonuc}

Sonuç olarak yaptığımız çalışmada, acil servise hipertansiyon tanısı ile bir yılda iki ve üzerinde başvurunun sık olduğu gösterilmiştir. Spesifik koruyucu kardiyoloji eğitim hemşiresi programının yaygınlaşması ile bu hastaların hekimleri ile yeterli zaman ayrılarak bilgilendirme yapılması, gerektiği takdirde ikinci, üçüncü basamaktaki hekimlerle koordinasyonu sağlanarak takipleri bu hastaların acil servise başvuru sıklığını azaltabilir.

Referanslar

1.Ettehad, D, Emdin, CA, et al, Blood pressure lowering for prevention of cardiovascular disease and death: a systematic review and meta-analysis, Lancet, 2016, 387, 957-967.

2. Whelton, PK, Carey, RM, et al, Guideline for the Prevention, Detection, Evaluation, and Management of High Blood Pressure in Adults: Executive Summary: A Report of the American College of Cardiology/American Heart Association Task Force on Clinical Practice Guidelines, High Blood Pressure Clinical Practice Guideline, Hypertension, 2018, 71(6), 1269-1324.

3. Williams, B, Mancia, G et al, Guidelines for the management of arterial hypertension. The Task Force for the management of arterial hypertension of the European Society of Cardiology (ESC) and the European Society of Hypertension (ESH), European Heart Journal, 2018, 39, 3021-3104.

4. Brunstrom, M, Carlberg, B, Association of blood pressure lowering with mortality and cardiovascular disease across blood pressure levels: a systematic review and meta-analysis, Journal of American Medical Association Internal Medicine, 2018, 178, 28-36.

5. Bohm, M, Schumacher, H, et al, Achieved blood pressure and cardiovascular outcomes in high-risk patients: results from ONTARGET and TRANSCEND trials, Lancet, 2017, 389, 22262237.

6. Chow, CK, Teo, KK, et al, Prevalence, Awareness, Treatment, and Control of Hypertension in Rural and Urban Communities in High, Middle-, and Low-Income Countries, Journal of American Medical Association, 2013, 310(9), 959-968.

7. Arıcı, M, Birdane A, et al, Türk hipertansiyon uzlaşı raporu, Türk Kardiyoloji Derneği Arşivi, 2015, 43(4), 402-409.

8. Xu, T, Wang, Y et al, Survey of Prevalence, Awareness, Treatment, and Control of Hypertension Among Chinese Governmental and Institutional Employees in Beijing, Clinical Cardiology, 2010, 33(6), E66-72.

9. Altun, B, Arici, M et al, Prevalence, awareness, treatment and control of hypertension in Turkey (the PatenT study), 2005 , Journal of Hypertension, 23, 1817-1823.
10. He, J, Muntner, P et al, Factors Associated with hypertension control in the general population of the United States. Archives of Internal Medicine 2002, 162 (9), 1051-1058.

11. Zoungas, S, Chalmers, J, et al, Follow-up of blood-pressure lowering and glucose control in type 2 diabetes. New England Journal of Medicine, 2014, 371, 1392-1406

12. Filipovsky, J, Seidlerova, J et al, Automated compared to manual office blood pressure and to home blood pressure in hypertensive patients. Blood Press, 2016, 25, 228-234.

13. Bliziotis, IA, Destounis, A et al, Home versus ambulatory and office bloodpressure in predicting target organ damage in hypertension: a systematic review and meta-analysis. Journal of Hypertension, 2012, 30, 1289-1299.

14. Dickinson, HO, Mason, JM et al, Lifestyle interventions to reduce raised blood pressure: a systematic review of randomized controlled trials, Journal of Hypertension, 2006, 24, 215-233.

15. Fletcher, BR, Hartmann-Boyce, J et al, The effect of selfmonitoring of blood pressure on medication adherence and lifestyle factors: a systematic review and meta-analysis. American Journal of Hypertension, 2015, 28, 1209-1222.

16. Gülpınar, MA, Gürpınar, E et al, Mezuniyet Öncesi Tıp Eğitim Ulusal Çekirdek Eğitim Programı - 2014. http://www.ktu.edu.tr/dosyalar/medtip_752c6.pdf

17. Bakris, G, Ali, W et al, ACC/AHA versus ESC/ESH on hypertension guidelines, JACC guideline comparison, Journal of American College of Cardiology, 2019, 73, 3018-3026.

18. Zernike, W, Henderson, A, Evaluating the effectiveness of two teaching strategies for patients diagnosed with hypertension, Journal of Clinical Nursing, 1998, 7, 37-44.

19. Yıldırım, JG, Çevirgen, A, Kronik hastalıkların yönetiminde kullanılan bilișim tabanlı uygulamalar, Celal Bayar Üniversitesi Sağllk Bilimleri Enstitüsü Dergisi, 2019, 6(1), 65-73.

http://edergi.cbu.edu.tr/ojs/index.php/cbusbed isimli yazarın CBUSBED başlıklı eseri bu Creative Commons Alıntı-Gayriticari4.0 Uluslararası Lisansı ile lisanslanmıștır. 